КИСЛЯКОВ Анатолий Сергеевич - кандидат исторических наук, доцент департамента социологии, истории и философии Финансового университета при Правительстве РФ (125993, Россия, 2. Москва, Ленинградский np-кт, 49; askislyakov@fa.ru)

ИЩЕНКО Артем Дмитриевич - студент международного финансового факультета Финансового университета при Правительстве РФ (125993, Россия, г. Москва, Ленинградский пр-кт, 49; artem. lemars@mail.ru)

\title{
ОСОБЕННОСТИ УНИВЕРСИТЕТОВ ТРЕТЬЕГО ПОКОЛЕНИЯ В УСЛОВИЯХ РАЗВИТИЯ ЧЕТВЕРТОЙ ПРОМЫШЛЕННОЙ РЕВОЛЮЦИИ
}

\begin{abstract}
Аннотация. В статье анализируется сущность университетов третьего поколения, их отличия от университетов предыдущих поколений. Авторы, описывая данный тип университетов, приводят примеры различных образовательных учреждений. В статье описана важность трансформации университетов в модель третьего поколения в рамках развития четвертой промышленной революции.

Ключевые слова: промышленная революция, университеты третьего поколения, ноу-хау, технополис, исследовательская деятельность, инновации
\end{abstract}

$\mathrm{P}$ азмер, масштаб и скорость технологических изменений четвертой промышленной революции ставят на повестку дня вопрос о поиске наиболее успешных моделей управления в сфере образования. Дело в том, что в современном глобальном и цифровом мире успех в конкуренции между странами, организациями и людьми все больше определяется их способностями, возможностями и скоростью саморазвития, которые закладываются в т.ч. через систему образования.

Особенность современной системы образования состоит в том, что на университеты возлагается новая, ранее не характерная для них задача: они должны стать катализаторами развития инновационной экономики. Для этого университеты сами должны претерпевать обновление, сопоставимое по масштабам и сложности с трансформацией, происходящей на наших глазах, например в сфере государственного управления. То же относится и к школе, которая должна сама быть максимально гибкой, удовлетворять спрос на персонализированное образование и готовить будущие поколения к скорости происходящих изменений.

Мы остановимся на университетах, которые претерпевают существенную трансформацию, состоящую в переходе к модели университета третьего поколения. Согласно этой теории [Виссема 2016; Андреев 2009; Аврус 2001] раз-

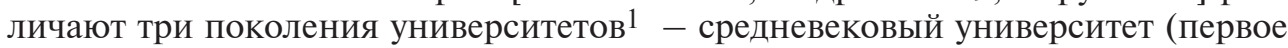

\footnotetext{
${ }^{1}$ A History of the University in Europe (ed. by W. Ruegg). Vol. 1-4. Cambridge: Cambridge University Press.
} 2003-2011. 
поколение $)^{1}$, гумбольдтовская модель (второе поколение) ${ }^{2}$ и университет третьего поколения. Ключевое отличие озвученных трех типов университетов друг от друга состоит в основных целях их деятельности. Граница отличий также проходит по другим направлениям: по методам исследований, роли в обществе, даже по тому, кого выпускают из университетов.

Характерным признаком университета третьего поколения является наличие соответствующей инфраструктуры, позволяющей формировать вокруг или около него целый кластер высокотехнологичных компаний, в которых университет владеет ноу-хау (результатами научной работы) и которые появляются по инициативе ученых или по решению университета.

Хорошим примером университета с вековой традицией, прошедшего полный путь трансформации в сторону модели третьего поколения, является Кембриджский университет ${ }^{3}$.

Современный Кембриджский университет мало отличается от средневекового: в 31 колледже собран полный набор факультетов и специализаций по естественным и гуманитарным наукам 4 . Кардинальные изменения начались в 1992 г., когда был назначен новый вице-канцлер - по сути, профессиональный управленец (менеджер) университета. Ранее эту должность занимал декан одного из колледжей, в течение 2 лет совмещая управленческие функции с основной академической деятельностью.

Далее, сэр Алек Броерс, который занимал пост вице-канцлера с 1996 по 2003 г., развернул крупномасштабное сотрудничество с промышленными компаниями. При этом нашлись оппоненты его подхода, которые видели в этом ущемление академических свобод. Однако, как показала дальнейшая практика, данное сотрудничество прямо соответствовало потребностям развития университета, и прежде всего - задаче обеспечения финансовой устойчивости, поскольку для сохранения лидерства требовалось куда более солидное финанси-

1 Первые университеты берут свое начало в латинских школах, наследниках платоновской Академии и Ликея Аристотеля, а также в деятельности знаменитых преподавателей древности. «Латинские школы» появились в Европе в период раннего Средневековья. После принятия на континенте христианства рядом с крупными храмами или монастырями стали открываться школы, в которых все лекции велись на латыни (отсюда и название школ). Однако ранние университеты возникли не вследствие трансформации латинских школ, а выросли из формирующейся в этот период практики чтения публичных лекций, разрешение на которые выдавали городские власти и церковь. Конечная цель по сравнению с латинскими школами не изменилась - трансляция уже существующих знаний, которые к тому же могут быть утрачены [Виссема 2016: гл. 1].

2 Эта модель получила свое название по имени основателя Берлинского университета (1810 г.), который позже был назван в его честь, Вильгельма фон Гумбольдта, прусского дипломата, основателя современной лингвистики, философа эпохи Просвещения, министра образования в постнаполеоновском правительстве Пруссии. В университетах подобного типа образование было интегрировано с научными исследованиями, причем студентам и ассистентам изначально поручалось выполнение все более широкого круга обязанностей, что соответствовало средневековой традиции ремесленных гильдий, члены которых проходили путь от ученика к подмастерью и далее к мастеру. Научные исследования были основаны на рациональном подходе, экспериментах, строгой аргументации и открытости для дискуссий, которая давала возможность проверки и развития полученных результатов другими учеными. Научные выводы могли делаться только на принципах системности и рациональности. Результаты должны быть доступными всем для верификации. Такие университеты являются алтарем чистой науки («науки для науки»), и главной их целью был прогресс науки [Виссема 2016: гл. 1].

3 Практика отпочкования (это явление получило название «спин-аут») от Кембриджа созданных при его участии компаний началась с таких фирм, как Cambridge Instruments (основана в 1881 г. Горацием Дарвином - сыном Чарльза Дарвина) и Pye Radio (основана в 1896 г. в тесной связи с Кавендишской лабораторией университета; в 1960 г. ее поглотила компания Philips Electronics) [Виссема Й. 2016: гл. 2.1].

4 Число студентов (всех уровней обучения) - чуть более 18 000; преподавателей и административного персонала 11000 человек. См.: Официальный сайm University of Cambridge. URL: http://www. cam.ac.uk/about-the-university/how-the-university-and-colleges-work?ucam-ref=global-header (accessed 23.07.2019) 
рование, нежели то, которое готово было предоставить правительство. В итоге университет заключил договоры на проведение совместных исследований с такими компаниями, как BP, Glaxo, Hitachi, Microsoft, Rolls-Royce, Seiko, Toshiba, Unilever и другими компаниями [Виссема 2016: 81-93].

После того как в 1997 г. Гордон Браун стал министром финансов Великобритании, он инициировал создание Инновационного фонда высшего образования (Higher Education Innovation Fund, HEIF), а позднее - Совета по финансированию высшего образования (Higher Education Funding Council for England, $H E F C E)^{1}$. В дальнейшем эти фонды оказали прямую поддержку в организации 8 центров предпринимательства, один из которых открылся в Кембриджском университете. Одновременно с открытием центра предпринимательства были выделены средства на формирование Фонда решения сложных задач (The University of Cambridge Challenge Fund) ${ }^{2}$ и Центра трансфера технологий (The Centre for Technology Management) ${ }^{3}$. Так были заложены основы дальнейшего развития университета.

В 1999 г. Кембриджский университет объединил все эти структуры в одну корпорацию под названием Cambridge Enterprise. Ее основной целью стало создание бизнес-инкубатора и управление им. Помимо этого, Cambridge Enterprise предоставляла так называемые посевные инвестиции, а также занималась обучением студентов предпринимательству 4 . Кроме того, в обязанности Cambridge Enterprise входит защита принадлежащих университету прав интеллектуальной собственности, для чего была образована компания Cambridge University Technical Services Ltd 5 . Также в целях коммерциализации результатов интеллектуальной собственности Cambridge Enterprise заключает лицензионные соглашения и помогает создавать новые компании.

В 2003 г. на средства государственного гранта Кембриджский университет создал еще одну структуру - Центр изучения предпринимательства (The Entrepreneurship Centre) ${ }^{6}$, в котором уже в 2006 г. читались около 30 курсов по предпринимательству ${ }^{7}$. Еще одним важным событием стало образование Института управления производством (Institute for Manufacturing) ${ }^{8}$, который занимается научно-исследовательской и академической деятельностью на стыке двух видов дисциплин - инженерных и управленческих наук.

В итоге кембриджский технополис функционирует как сеть организаций, оказывающих поддержку предпринимателям. Определяющим, на наш взгляд, является то, что большую часть интеллектуальной собственности университет оставляет ее инициаторам - преподавателям и студентам. Безусловно, последний факт стимулирует ученых открывать новые компании, что, в свою очередь, приносит выгоду и университету.

Конечно, все университеты так или иначе продают или безвозмездно передают созданные ими ноу-хау бизнесу и государственным организациям. Некоторые университеты делают это в форме консультаций, другие - за счет продажи патентов или проведения программ повышения квалификации для заинтересованных

\footnotetext{
1 Деятельность обеих организаций финансируется казначейством. URL: http://www.hefce.ac.uk/ke/ heif/previous/ (accessed 21.07.2019).

2 https://www.enterprise.cam.ac.uk/news/cambridge-challenge-fund-marks-ten-years/ (accessed 21.07.2019).

3 http://www.ifm.eng.cam.ac.uk/research/ctm/ (accessed 21.07.2019).

4 https://www.enterprise.cam.ac.uk/who-we-are/our-film/ (accessed 21.07.2019).

5 https://www.endole.co.uk/company/05749230/cambridge-university-technical-services-limited (accessed 21.07.2019).

6 https://www.jbs.cam.ac.uk/entrepreneurship/ (accessed 21.07.2019).

7 https://www.jbs.cam.ac.uk/entrepreneurship/programmes/ (accessed 25.07.2019).

8 http://www.ifm.eng.cam.ac.uk (accessed 25.07.2019).
} 
структур. Более того, в университетах второго поколения часто можно найти бизнес-инкубаторы и другую инфраструктуру поддержки начинающих предпринимателей. Разница состоит в том, что для университетов гумбольдтовской модели коммерциализация знаний была и остается личным делом преподавателя. Чаще этот вид деятельности был связан с интересной, но в значительной степени побочной активностью, которая к тому же дозволялась только до тех пор, пока она не вступала в противоречие с основной научно-педагогической деятельностью ${ }^{1}$. Для университетов третьего поколения ситуация качественным образом отличается. Для них коммерциализация является одним из основных видов деятельности, которые нормативно им предписаны. На университетах лежит обязательство по извлечению прибыли из создаваемых ими знаний. Здесь в качестве примера можно привести Бандунгский технологический университет (БТИ), который на уровне уже своих программных документов осознает, что экономика Индонезии может стать инновационной, только если страна избежит роли рынка сбыта для международных корпораций. В связи с этим БТИ видит свою главную задачу в извлечении выгоды из своих ноу-хау².

Следующей особенностью университетов третьего поколения является то, что они теперь действуют на международном высококонкурентном рынке. Университетам приходится соперничать за лучших преподавателей, за самых талантливых студентов и за исследовательские контракты с компаниями. Не все так пессимистично, как может показаться на первый взгляд, - этот же рынок способствует постоянному обмену опытом и тесному сотрудничеству. В результате университеты третьего поколения являются своего рода сетевыми организациями и в силу этого реализуют партнерство с бизнесом, инвесторами, негосударственными учреждениями, а также другими университетами через свои так называемые карусели ноу-хау.

«Карусель ноу-хау» (или «хаб ноу-хау») - термин, появившийся в зарубежной литературе и описывающий процесс, в результате которого университеты сами берут на себя инициативу превращения в хаб, объединяющий различные организации, участвующие в создании и коммерциализации ноу-хау. Иногда такой центр может получить международное признание в качестве флагмана в создании знаний в конкретных научных областях. Ролевыми моделями для университетов третьего поколения здесь являются Стэнфордский университет с его Кремниевой долиной, Кембриджский университет с его дочерней компанией Cambridge Enterprise, Левенский католический университет с его предпринимательской дочерней компанией Leuven $R \& D$, а также ИТ-парком $I M E C$, Национальный университет Сингапура с его дочерней компанией NUS Enterprise, Вагенингенский университет в Нидерландах с его известной Продовольственной долиной и многие другие университеты.

В основе концепции карусели ноу-хау лежит понимание того, что научные исследования на современном этапе развития общества возможны лишь при плотном взаимодействии с уже существующими и недавно созданными компаниями, а также с другими типами научно-исследовательских организаций.

\footnotetext{
1 В СМИ можно найти множество характерных примеров. Один из них - статья про разработку компактной кардиофлешки. См.: Выбирай сердцем: как российская кардиофлешка добралась до Зимбабве. - РБК. 26.04.2017. Доступ: http://www.rbc.ru/own_business/26/04/2017/58fdb5ef9a79477c29d еа251 (проверено 10.11.2019).

2 Бандунгский технологический институт, основан в 1920 г., является старейшим университетом Индонезии и одним из ведущих технологических университетов Азии. Он может похвастаться множеством успешных выпускников, включая первого президента страны Сукарно. В отличие от большинства индонезийских университетов, у БТИ имеется сильная научно-исследовательская база, отличные международные связи и сильная ассоциация выпускников. См. Oфициальный сайт Institut Teknologi Bandung. Доступ: http://infopublik.itb.ac.id/ (проверено 20.07.2019).
} 
Еще одна характеристика университета третьего поколения состоит в том, что научные исследования носят в значительной степени междисциплинарный характер (иногда в зарубежной литературе речь идет о трансдисциплинарных исследованиях, что, собственно, одно и то же). Движущей силой подобных университетов наряду с рациональным научным методом становятся такие понятия, как «единение и креативность». В книге обладателя двух Пулитцеровских премий профессора Гарвардского университета Э.О. Уилсона «Единение: слияние знаний» [Wilson 1999] предложена интересная трактовка термина «единение» (англ. consilience), которое он определяет как слияние знаний или соединение по нескольким дисциплинам. Подобная трактовка вполне соответствует действительности.

К особенностям университетов третьего поколения также относится их двунаправленность. С одной стороны, университет занимается созданием особых условий для ведущих ученых в рамках реализации их проектов, с другой - поддержкой наиболее талантливых студентов и реализацией программ массового высшего образования. Университеты в этом плане имеют несомненное преимущество, т.к. обладают одним и тем же ресурсом дважды: участники университетской платформы не только производят, но и потребляют полученные внутри университета знания.

Наконец, заключительной отличительной чертой университетов третьего поколения является диверсификация каналов их финансирования. Считается, что у университетов должно быть как минимум 4 источника финансирования: плата за обучение, гранты на научные исследования, доходы от коммерческой деятельности, фонды целевого капитала. В условиях сокращения государственного финансирования высшего образования университеты вынуждены взять на себя задачи, связанные с поиском и привлечением денежных средств.

Ввиду обозначенных выше особенностей именно модель университета третьего поколения представляется наиболее оптимальной с точки зрения эффективного управления высшим образованием в условиях развития четвертой промышленной революции. При этом важно отметить, что это модель, а не четко сформулированный набор инструкций, обязательных к исполнению. Ее конкретное воплощение, особенно с учетом скорости происходящих изменений, должно иметь множество вариаций.

Модель университета третьего поколения позволит ответить на те вызовы, с которыми столкнулись высшие учебные заведения всего мира, а именно увеличение стоимости научных исследований, усиление конкуренции в глобальном масштабе, понимание университета как инструмента экономического роста (изменения в государственной политике), междисциплинарный характер проводимых исследований, массовый рост числа студентов.

\section{Список литературы}

Аврус А.И. 2001. История российских университетов. М.: Московский общественный научный фонд. 85 с.

Андреев А.Ю. 2009. Российские университеты ХVIII- первой половины ХІХвека в контексте университетской истории Европы. М.: Знак. 648 с.

Виссема Й. 2016. Университет третьего поколения. Управление университетом в переходный период. М.: Олимп-Бизнес. 480 с.

Wilson E.O. 1999. Consilience: The Unity of Knowledge. N.Y.: Vintage Books, a Division of Random House, Inc. 368 p. 
KISLYAKOV Anatoliy Sergeevich, Cand.Sci. (Hist.), Associate Professor of the Department of Sociology, History and Philosophy, Financial University under the Government of the Russian Federation (49 Leningradsky Ave, GSP-3, Moscow, Russia, 125993; askislyakov@fa.ru)

ISHCHENKO Artyom Dmitrievich, student of the International Financial Faculty, Financial University under the Government of the Russian Federation (49 Leningradsky Ave, GSP-3, Moscow, Russia, 125993; artem.lemars@mail.ru)

\title{
FEATURES OF THE THIRD GENERATION UNIVERSITIES DURING THE DEVELOPMENT OF THE FOURTH INDUSTRIAL REVOLUTION
}

\begin{abstract}
In the article, the authors analyze the essence of the third generation universities and their differences from universities of previous generations. Describing this type of universities, the authors show examples of different educational institutions. Moreover, they show the importance of the transformation of universities to the third generation model. Keywords: industrial revolution, third generation universities, know-how, technopolis, research activity, innovations
\end{abstract}

РОДИНОВА Надежда Петровна - доктор экономических наук, профессор кафедры педагогики и психологии профессионального образования Московского государственного университета технологий и управления им. К.Г. Разумовского» (ПКУ) (109004, Россия, г. Москва, ул. Земляной Вал, 73; rodinovanp@mgutm.ru)

АЩАУЛОВ Роман Викторович - магистр Московского государственного университета технологий и управления им. К.Г. Разумовского (ПКУ) (109004, Россия, г. Москва, ул. Земляной Вал, 73)

\section{ОСОБЕННОСТИ ИССЛЕДОВАНИЯ СОЦИАЛЬНО-ПСИХОЛОГИЧЕСКОЙ АДАПТАЦИИ СОТРУДНИКОВ НА ПРИМЕРЕ ЮВЕЛИРНОЙ КОМПАНИИ}

Аннотация. В статье рассматривается понятие и сущность социально-психологической адаптации сотрудников, основные аспекты наиболее популярных методик диагностики социально-психологической адаптации сотрудников К. Роджерса и Р. Даймонда, А.Г. Маклакова и С.В. Чермянина. Авторы обосновывают выбор методики К. Роджерса и Р. Даймонда для проведения исследования социально-психологической адаптации сотрудников ювелирной компании и демонстрируют применение выбранной методики в контексте проведения опроса ее новых сотрудников. В статье представлены результаты анализа полученных данных и выявлены слабые стороны функционирования системы социально-психологической адаптации, обоснованы предложения мероприятий для трансформации слабых сторон в соответствующие норме.

Ключевые слова: социально-психологическая адаптация, методики диагностики социально-психологической адаптации, адаптационные возможности, опрос новых сотрудников, показатели адаптации, адаптационный тренинг

$\mathrm{C}$ оциально-психологическая адаптация выступает неотъемлемой частью процесса адаптации нового сотрудника. Она характеризуется приспособлением новичка к гармоничной профессиональной жизнедеятельности в организации с целью объединения соответствия требований организации, коллектива и удовлетворения собственных профессиональных потребностей, интересов и мотивов. Адаптивность личности к организационному соци- 